$\overline{\text { INVITED LECTURE }}$

\title{
The Mission of Therapeutics
}

David J. Kupfer, M.D.

Gerald Klerman's career as a researcher was marked by a strong interest in mood disorders. He was particularly interested in pathways to depressive episodes and their treatment. In this lecture entitled "The Mission of Therapeutics," the emphasis is placed on the integration of two developmental pathways representing biologic/genetic factors and psychosocial/environmental factors. Recent work on the role of childhood adversity and current stressors is reviewed, as well as biologic pathways and correlates. Finally, using treatment outcome as a window on pathogenesis is suggested as a strategy for understanding the interaction of biologic and psychosocial parameters in the onset of and recovery from episodes of depressive illness.

[Neuropsychopharmacology 9:169-180, 1993]
KEY WORDS: Depression; Development; Therapeutics; Stressors; Biologic correlates

\section{THE LEGACY OF GERALD KLERMAN}

As a clinical researcher with a life-time concern with treatment, Gerald Klerman was ahead of his time in attempting to integrate diverse approaches to understanding psychiatric disorders and their treatment (Klerman 1975). This notion of integration extended to the development of etiologic theories. His legacy is one that clearly demonstrates an interest in a wide range of psychiatric problems for which he always sought innovative solutions. His most important principle was that all of our work-basic, preclinical, and clinical-needed a strong empirical basis. He played a major role in the psychopharmacologic revolution and provided an important sobering balance during the early years of community psychiatry. His initial interests ranged from

From the Department of Psychiatry, University of Pittsburgh School of Medicine, Western Psychiatric Institute and Clinic, Pittsburgh, Pennsylvania.

Address correspondence to: David J. Kupfer, M.D., Department of Psychiatry, University of Pittsburgh School of Medicine, Western Psychiatric Institute and Clinic, 3811 O'Hara Street, Pittsburgh, Pennsylvania 15213.

Received March 23, 1993; revised July 8, 1993; accepted July 9, 1993. Presented at the 1992 ACNP Annual Meeting, held in San Juan, Puerto Rico, December, 1992: "The First Gerald Klerman Memorial lecture." schizophrenia to affective disorders. When he moved from Yale University to Harvard College, he continued several sets of collaborative studies with Dr. Myrna Weissman that ultimately led to a greater understanding of the long-term course of mood disorders as well as to the development and implementation of a major form of psychotherapy known as interpersonal psychotherapy (IPT) (Klerman 1983; Klerman et al. 1984).

The collaborative depression studies sponsored by the National Institutes of Mental Health (NIMH) in which he was a principal investigator have produced numerous insights in our understanding of personality, genetics, psychopathology, and the long-term prognosis of the serious mood disorders. The emphasis on longitudinal studies was also reflective of his interest in disorders across the life cycle. As a teacher, he provided inspiration for students and a role model for young investigators. He was an ombudsman for clinical researchers, with particular emphasis on quality. While Dr. Klerman was always a model of personal courage, he also demonstrated extraordinary intellectual courage. This, in turn, allowed him to show appropriate levels of skepticism while encouraging investigators to maintain their convictions until disproven. He sought to facilitate treatment research at NIMH and elsewhere, setting standards for multisite collaborative studies, whether they were sponsored by federal agencies or by the pharmaceutical industry. Indeed, he led the way in developing intellectual dialogue with the 
pharmaceutical industry. His interest in treatment research and his notion that demonstrated efficacy should provide the basis for public policy stimulated his own interest in the translation of scientific knowledge to public policy.

As we wrestle in the 1990s with immediate concerns that are scientific, economic, and political, we need to remember that Gerald Klerman would push us to work on the future, to work on new opportunities, and to be aware of our limitations while seeking to remove impediments (Klerman 1990). It is to his most important contribution to psychiatry that this lecture is dedicated. Because he was my first clinical supervisor as a psychiatric resident, it would only be consistent if my lecture were to focus on the mission of therapeutics and models of research that will help us with this mission.

My own interest in treatment has always been mixed with a parallel interest in psychobiology. While I have been interested in the pathogenesis of disorders, I have also been concerned about the relationship of pathogenesis to treatment and prognosis. The strategies developed by Gerald Kerman have provided much of the intellectual climate in which it has been possible to integrate biology and treatment. Early on, many of us emphasized so-called cross-sectional research, studies limited to the episode of illness. Later, we came to understand the importance of following individuals longitudinally to understand the disorder fully. This has provided a strong stimulus to develop longitudinal designs. However, the ideal longitudinal study cannot be conducted by beginning with subjects in whom the disorder has already developed. Due to an interest in illness trajectories and pathways to the onset of disorders, perhaps this lecture should be subtitled "The Road to Depression" because we will review models that provide an integrated view of vulnerability factors from both psychosocial and biologic domains. Such models may help us to understand how, after the illness begins, we can provide interventions that improve our level of treatment efficacy. Thus, the reason for emphasis on those events and changes that occur long before the disorder becomes apparent.

\section{VARYING PATHWAYS TO DEPRESSION}

Most scientists today would concur that one needs to consider at least two strands of investigative activity that might provide important insights regarding pathways to depression. One strand is often characterized as representing biologic genetic domains and the other representing psychosocial/environmental domains. The balance between vulnerability and protective factors in each of these domains and across domains is not completely known. One school of thought argues that provoking agents in the environment (in the form of stressful life events and chronic difficulties) is a major determinant of what leads an individual with the right set of vulnerability factors to develop an onset of depres sion (Brown and Harris 1978). Other researchers do not subscribe to the provoking agent model, viewing the risk factors as exclusively biologic in nature. My own view is that both biologic/genetic factors and the psy. chosocial/environmental factors play a role in the pathway to depression. Finally, in disorder in which females predominate by a ratio of at least $2: 1$, the roleof gender must be integrated into any explanatory model. Given the complexity of this issue, the reader is directed to a recent review of this important issue (Frank, submitted).

With respect to those biologic/genetic areas that traditionally attract investigative talent, at least three major areas should be included: (1) biological clocks or rhythms, (2) the neurobiology of stress, and (3) temperament (Moore 1991). A number of researchers believe that even at an early stage of development, instability with respect to biologic rhythms (which could be reflected as a developmental lag in the biologic clock), may represent a vulnerability factor for the development of clinical depression. In a similar vein, researchers involved in stress physiology and reactivity point to data in childhood and adolescence, as well as in young adults that support the idea that such measures may reflect vulnerability factors for the onset of depres sion. In the area of temperament, highly heritable traits such as shyness and negative self-evaluation kindled the interest of numerous investigators (Kagan et al. 1988; Kagan and Snidman 1991a). Indeed, Kagan and colleagues (Kagan and Snidman 1991b) have sought to integrate behavioral data with measures of physiologic stress observed in children with very high levels of social inhibition. However, up to now relatively few groups have sought to integrate the diverse areas that are representative of the biologic/genetic domain. $\mathrm{Re}-$ cently, there has been some interest in examining young infants who may be at later risk for affective disorders (Dawson et al. 1992a, 1992b).

On the other hand, a considerable body of literature has been written to demonstrate that early developmental experiences are key, perhaps necessary, ingredients in the later development of depression. One research group has categorized such experiences under the rubric of childhood adversity, in which they include early loss of mother (not necessarily the actual loss of mother, but the functional loss of mother), physical and sexual abuse as well as parental indifference or neglect (Brown et al. 1986). Although the specificity of these factors as leading to depression rather than other adolescent or adult psychopathology is debated, there is little question that these early developmental experiences do play a role in the onset of depression in numerous individuals (Bifulco et al. 1991). 
The challenge then becomes one of attempting to integrate factorsfrom these two domains in understanding the onset of depression. If we can assume that a potential interplay occurs across domains, we can ask the following types of questions. Do early environmental stresses have differential importance with respect to later development of disorder? Do they have differential importance at different "critical" points in development? Given the fact that such stresses are superimposed on a developing biologic substrate, are they significantly more important at ages 4 to 7 years than when the individual has reached the increased level of biologic maturation achieved by age 11 to 13 years? We also need to understand more about whether most environmental stresses are experienced as more pervasive for an infant or a very young child. For example, does the young child's inability to understand the exact nature and extent of a brief separation lead to a perception of "abandonment," which would not be experienced by an older child? Much more needs to be investigated with respect to early cognitive and emotional development to tease out these issues.

We also do not know whether specific types of environmental stresses produce specific changes in cortical and subcortical substrates. As the central nervous system develops, specific brain regions may have greater responsibility, but not necessarily greater plasticity, in dealing with these additional "challenges." A desire among basic neuroscientists to investigate these questions in primate and rodent models has led to a variety of studies suggesting models for "human depression" involving learned helplessness and separation paradigms (Koob et al. 1989). Unfortunately, only recently has this research, although often elegant, incorporated a developmental perspective for such behavioral and neurochemical strategies (Kraemer 1992). However, we still do not have sufficient information to be convinced of these interrelationships. We are left with abiding questions concerning whether these stresses provide a form of priming or early scarring with respect to he development of depression.

Just as we might also ask about the effects of differential environmental stresses, we might pose the question as to whether differential biologic endowment, such as temperamental attributes or genetic stability in rhythms, will determine a different response to the same stressor and thus differentially predispose to psychopathology. We believe that queries along these lines need to be addressed, and appropriate experiments need to be devised. The second related question concerning a form of "priming" is whether there is a normal range of biologic system fluctuations within which the biologic response to stresses can be absorbed and systems returned to homeostatic levels. Naturally, one would need to develop a template for the range and fluctuations of different systems, unless one assumes a "universal" response range independent of the specific biologic system. Then we are also left with the question raised earlier as to whether the repeated experience of the same or of different stresses can modify the biologic substrate. If we continue to envision this kind of interaction, we then begin to understand a priming activity in which repeated stress can have an increasing impact representing compounding or eventually a depletion of coping ability. In this way, we can ask whether beginning dysregulation of biologic systems leads to environmental effects? Does such dysregulation "create" life events or the perception that events are more stressful than earlier?

\section{ROLE OF CHILDHOOD ADVERSITY AND CURRENT STRESSORS}

The elegant work of Brown and coworkers (1986) has examined in detail childhood experience and the onset of depression. In this model, childhood adversity leads to an adverse adult life style, which, in the face of current provoking agents, may lead to the onset of depression. An example provided by the Brown group of the environmental pathway would be to posit the link between neglect by parents, premarital pregnancy, and early marriage to an undependable man leading to subsequent marital difficulties. There is, however, an additional strand through which childhood adversity might lead to a "cognitive bias," such as low self-esteem or negative self-evaluation. This cognitive bias, in turn, also provides an adult vulnerability that may indeed lead to the onset of depression. Brown and others have argued that on this "cognitive pathway," negative childhood experience is associated with a "helpless cognitive set," which interferes with the development of successful coping strategies and supportive relationships. The lack of such support, in turn, increases risk for depression once a stressor arises. This view has been adapted by American investigators who have provided confirmatory evidence for this pathway (Hammen 1992).

We now return to the question of whether dysregulation of both biologic systems and psychosocial systems eventually exerts an effect on life events themselves. We have very little data to suggest how we would even begin to examine whether a priming of biologic systems toward dysregulation has occurred, or whether the changes that have occurred in biologic systems have been followed by full recoveries or have produced scars that make the individual even more vulnerable to an initial episode of depression.

Recent data analyzed by Brown and colleagues (unpublished data) show that in adults, the presence of a severe event within 6 months of onset is unrelated to the severity of an initial episode of depression. The 
analysis of three different populations showed that both low-severity and high-severity first onset is associated with approximately a $60 \%$ likelihood of a severe event in the 6 months prior to onset (Table 1). However, if one examines a similar series of individuals who are experiencing their second or subsequent episode, the findings are different. In those individuals with a low level of severity (low melancholia score), $69 \%$ of these individuals had a severe life event within 6 months of depressive onset. On the other hand, among individuals with a high melancholia score, only $34 \%$ of individuals had experienced a severe life event; a rate not different from that observed in nondepressed subjects in the general population (Table 2). This finding is very consistent with the hypothesis that Post and others have proposed with respect to differences between first and subsequent episodes in terms of the likelihood of external provocation (Post 1992).

The study by Brown and colleagues on the issue of whether melancholic/endogenous depression is more associated with severe life events has been followed up by a recent study in Pittsburgh on recurrent depression. Frank and colleagues (unpublished data) have shown that there is a significant difference in the proportion of subjects experiencing a severe event in the 6 months before onset in individuals with research diagnostic criteria RDC endogenous subtype as compared with nonendogenous subtype ( $34 \%$ versus $56 \%, \chi^{2}=4.2$, $p=.04)$. Thus, we can tentatively conclude that life events occur quite frequently with the first episode, regardless of severity; but, after the first depressive episode they are not necessarily an associated feature of onset.

\section{BIOLOGIC PATHWAYS AND CORRELATES}

Although a number of other psychosocial factors could be discussed in detail, to simplify our argument, let us now turn briefly to the biologic domains. In examining the interaction between depression onset and under- lying biologic changes, it is useful to pose several questions. Our initial question is when do biologic correlates or stigmata present themselves in the lifetime course of depression? Perhaps an underlying assumption of this question is whether biologic changes associated or not associated with adult depression are present in child and adolescent depression. For decades we assumed that there were few similarities between sadness in childhood and adolescence and what weconsidered major depression in adulthood. The introduction of DSM-III and DSM-III-R nosology resulted in a conceptual shift, suggesting that childhood and adolescent depression shared most, if not all, the clinical features of adult depression. In the recent effort to diagnose childhood and adolescent disorders more accurately, perhaps we have presumed that if the clinical picture in childhood and adulthood is similar, then the associated and even underlying psychobiology should also be quite comparable. For example, Puig-Antich suggested that the clinical picture in child and adolescent depression would be reflected in similar biologic changes, particularly in sleep and neuroendocrine parameters (Puig-Antich 1986). However, his own early studies, as well as the results of others, have now pointed to the unlikeliness of neurobiologic similarity or constancy across the life span (Puig-Antich et al. 1982).

Thus, we are faced with a more intriguing set of questions. We need to take into account that there may be age-specific, gender-specific, developmentally phasespecific factors that affect the features of the clinical picture, its level of severity and the neurobiologic changes. But, perhaps the key question is when does the first neurobiologic system demonstrate correlates with clinical depression because it seems likely that there is a group of different neurobiologic systems, which reflect changes at different points in the life cycle.

The range of possible neurochemical and neurobiologic systems that could be implicated in mood disorders is extensive, and recentreviews in childhood and

Table 1. Presence of a Severe Event in 6 Months of Onset by "Melancholic/Psychotic" First Adult Onset Melancholic/Psychotic Score

\begin{tabular}{|c|c|c|c|c|}
\hline \multirow[b]{2}{*}{ Patient Series } & Low & High & \multirow[b]{2}{*}{ OR } & \multirow[b]{2}{*}{$p$} \\
\hline & \multicolumn{2}{|c|}{$\%$ Severe Event } & & \\
\hline North London & 71 & 59 & 1.75 & NS \\
\hline $\begin{array}{l}\text { Royal Free Hospital } \\
\text { (Calloway and Dolan) } \\
\text { Camberwell }{ }^{\star}\end{array}$ & $\begin{array}{l}50 \\
53\end{array}$ & $\begin{array}{l}60 \\
61\end{array}$ & $\begin{array}{l}0.67 \\
0.74\end{array}$ & $\begin{array}{l}\text { NS } \\
\text { NS }\end{array}$ \\
\hline Total & 59 & 60 & 0.95 & NS \\
\hline
\end{tabular}

* For the Camberwell general population, $18 \%$ (75/419) had a severe event.

${ }^{+} \mathrm{NS}=$ not significant.

Adapted from Brown et al. (unpublished data). 
Table 2. Presence of a Severe Event in 6 Months of Onset by "Melancholic/Psychotic" Nonfirst Adult Onset Melancholic/Psychotic Score

\begin{tabular}{|c|c|c|c|c|}
\hline \multirow[b]{2}{*}{ Patient Series } & Low & High & \multirow[b]{2}{*}{ OR } & \multirow[b]{2}{*}{$p$} \\
\hline & \multicolumn{2}{|c|}{ \% Severe Event } & & \\
\hline $\begin{array}{l}\text { North London } \\
\text { Royal Free Hospital }\end{array}$ & 74 & 22 & 9.80 & $<.01$ \\
\hline $\begin{array}{l}\text { (Calloway and Dolan) } \\
\text { Camberwell }{ }^{\star}\end{array}$ & $\begin{array}{l}54 \\
67\end{array}$ & $\begin{array}{l}27 \\
43\end{array}$ & $\begin{array}{l}3.17 \\
2.63\end{array}$ & $\begin{array}{l}\mathrm{NS}^{+} \\
\mathrm{NS}\end{array}$ \\
\hline Total & 69 & 34 & 4.33 & $<.001$ \\
\hline
\end{tabular}

* For the Camberwell general population, 18\% (75/419) had a severe event.

${ }^{\dagger} \mathrm{NS}=$ not significant.

Adapted from Brown et al. (unpublished data).

adolescence (Rogeness et al. 1992) have concluded that there may be a variety of abnormalities. Not surprisingly, the major areas that have received attention have centered around the hypothalamic-pituitary-adrenal (HPA) axis, rapid-eye movement (REM), and slowwave sleep physiology, and specific neurochemical/ neuropeptide challenge strategies.

In a series of elegant studies begun by the late Joaquim Puig-Antich and continued by key colleagues in Pittsburgh (Drs. NealRyanand Ronald Dahl) it has been demonstrated that if one examines 24-hour cortisol in prepubital children with clinical depression, no significant difference is observed in the 24-hour pattern compared to that of normal children (Puig-Antich et al. 1989). However among adolescents, there is a significant difference in the cortisol pattern in those individuals with a depression versus those who are studied as controls (Dahl et al. 1991). The 24-hour cortisol is significantly increased, especially during the presleep onset period in the early portion of the night (Fig. 1). If one examines adolescent depressed patients for 24hour cortisol, individuals with the high cortisol levels who also have short REM latency represent the majority of individuals with an elevated 24-hour cortisol (Fig. 2). From these investigations, we can conclude that in adolescents, there appears to be an emergence of cortisol changes in the hours before and after sleep onset (Fig. 3). In comparable data on sleep parameters, Dahl and colleagues (1990) have shown that prolonged sleep onset difficulty is also associated with a reduced time to the first REM period, so-called REM latency, which is frequently present in adolescent depressives. Nevertheless, despite these changes in the early phases of sleep, there does not appear to be any indication of re-

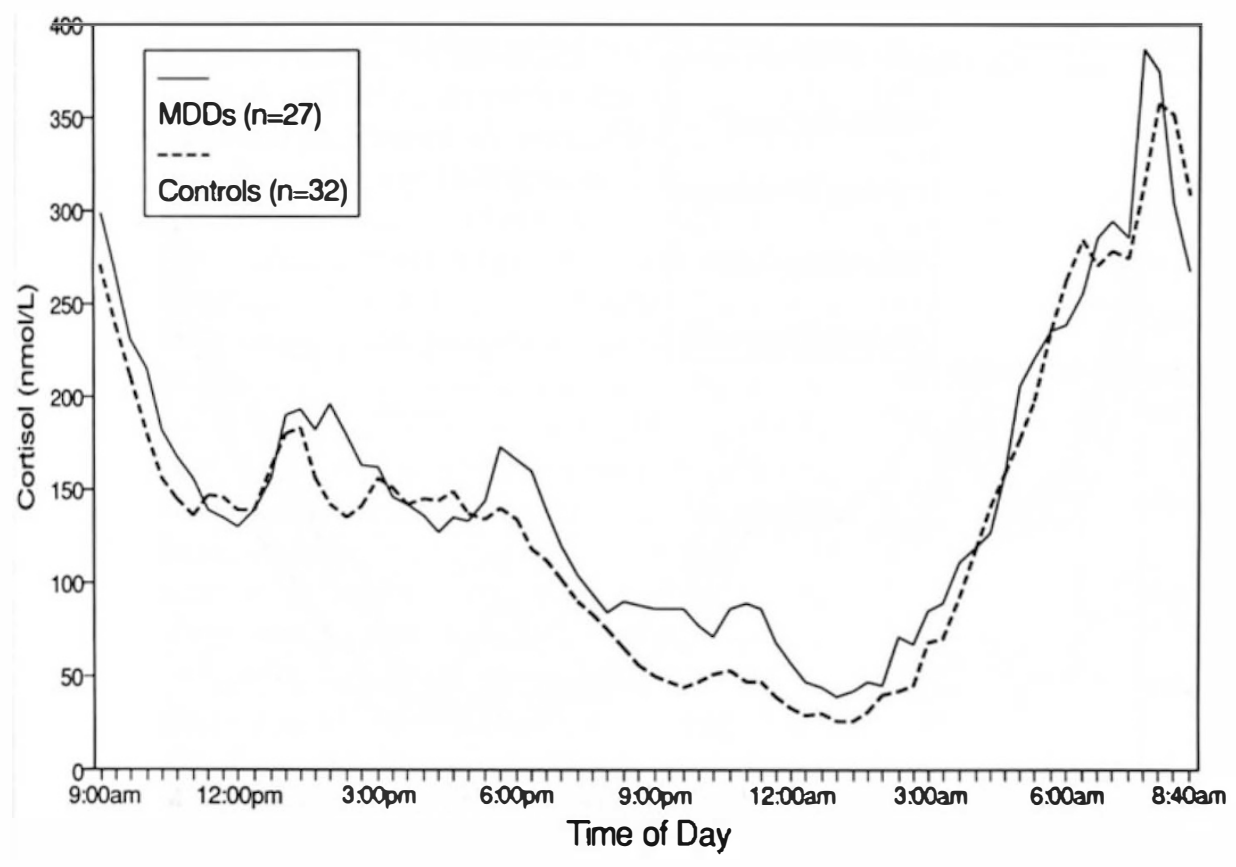

Figure 1. Twenty-four hour cortisol in adolescents aligned by clock time. $\mathrm{MDD}=$ major depressive disorders $(n=27)$; control $(n=32)$. Adapted from Dahl et al. 1991. 
Figure 2. Twenty-four hour cortisol (adolescents) aligned by clock time. $\mathrm{RL}=\mathrm{REM}$ latency $<75$ major depressive disorders (MDD) $(n=13) ; \mathrm{RL}$ $>75 \mathrm{MDD}(n=12)$; normals $(n=29)$. From Dahl et al. personal communication.

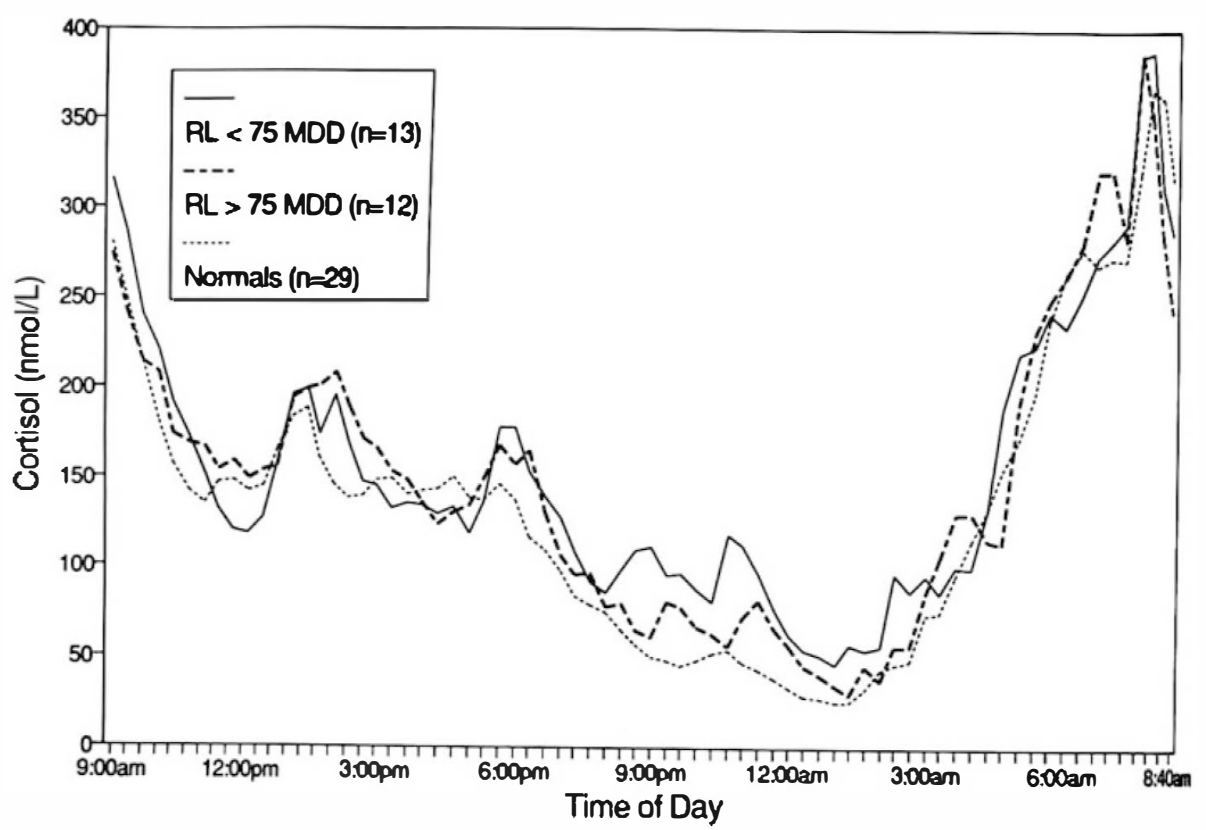

duced slow-wave sleep in these adolescent depressives as compared to control subjects (Kupfer and Ehlers 1989).

In contrast, if we examine the sleep of young adults, there are consistent findings demonstrating sleep differences between young adult depressives and young controls. Thus, it is only in the third decade that the sleep differences between controls and depressed patients become marked. Recent investigations have confirmed that this is true not just for the reduced REM latency but also increased density of REM sleep (Lauer et al. 1991) (Fig. 4). So, we can conclude that young adult depressives in their 20s show certain physiologic sleep findings that involve both REM and non-REM sleep abnormalities. As an important caveat, we need to realize that the majority of these results are derived from cross-sectional investigations with most of the data collected during the episode.

Although it has been well accepted that HPA axis changes occur in adult depressives (Sachar 1982), only
Figure 3. Twenty-four hour plasma cortisol concentrations aligned by clock time. MDD = major depressive disorders in adolescents (Adol) $(n=27)$; controls adol $(n=32)$; MDD in prepubertal (Prep) $(n=45)$; controls prep $(n=28)$. From Dahl et al. personal communication.

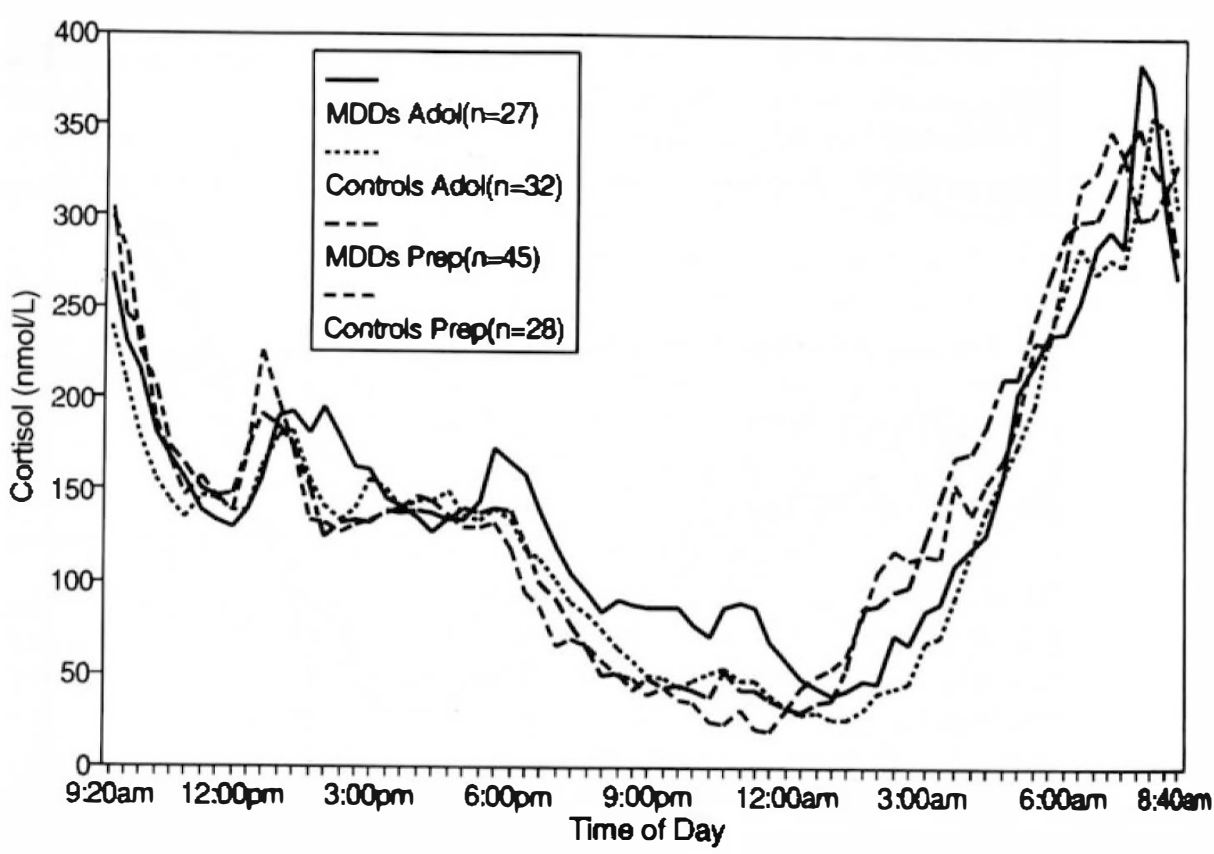




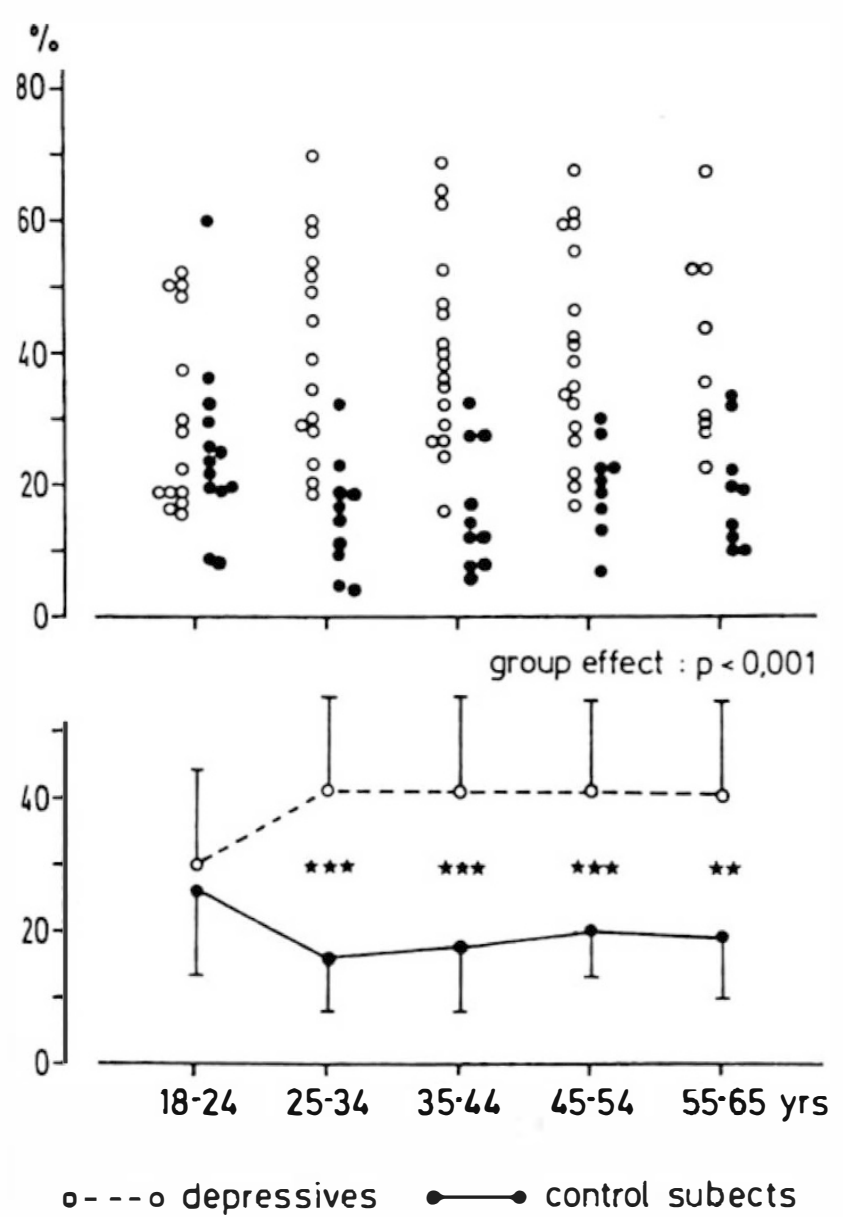

Figure 4. First REM density in percent. Adapted from Lauer et al. 1991.

recently has an extensive elegant reanalysis truly confrmed these findings. A metaanalysis by Van Cauter and colleagues (Van Cauter, personal communication, 1992) on samples derived from investigators around the world comparing depressed patients and age/gendermatched controls indicates a 24-hour mean cortisol level that is significantly elevated in depressed individuals irespective of age. This elevation reflects a failure to suppress nighttime concentrations and an elevated nadir of cortisol levels compared to that of controls. The relative rhythm amplitude (mean circadian amplitude, i.e., amplitude in percent of 24-hour mean level) seems to be dampened, and there is clearly more pulsatile cortisol variation. Finally, it appears that irrespective of age, the nadir occurs earlier in the depressed subjects. These findings support the concept that the 24-hour rhythm of cortisol levels, as a highly reproducible marker of human circadian rhythmicity, is reflective of circadian abnormalities in depression.

In attempting to present an overall framework with respect to psychobiologic correlates in depression, our

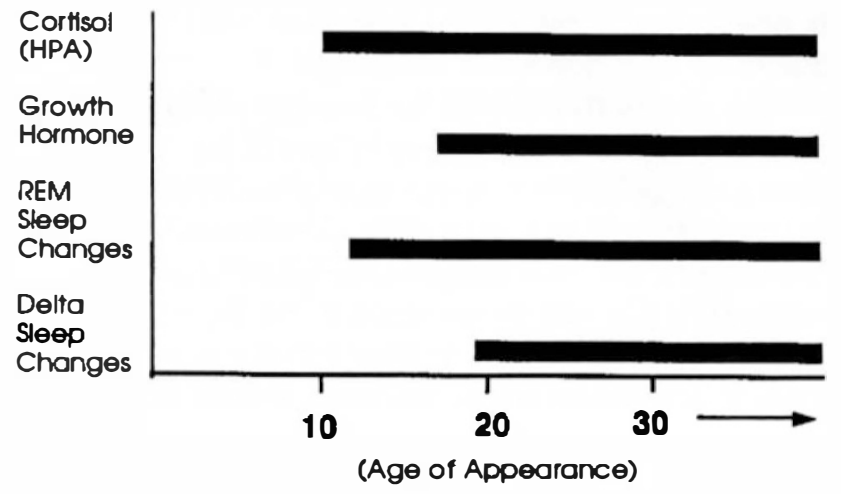

Figure 5. Psychobiologic correlates in depression.

best estimate at this point is that both initial HPA (cortisol) and REM sleep changes make their appearance between ages 10 and 20 years in individuals who are depressed and that slow-wave sleep changes and allnight growth hormone decreases or such alterations in response to probe strategies may not be apparent until age 20 or above. So, it is necessary to assume that a different set of neurobiologic findings may be present dependent on the age of onset of the initial depressive episode (Fig. 5).

As Post (1992) and others have indicated (Fig. 6), there appears to be a certain level of progression of state/trait phenomena over the course of affective illness. It is fair to say that a number of state or episoderelated changes involve both physiologic sleep changes as well as a number of neuroendocrine/neuropeptide changes. They may also include an increased level of corticotropin-releasing hormone (CRH), which is reflected in changes in cortisol, as well as alterations in thyroid-releasing hormone and growth hormone during the day. At the same time, reduced growth hormone

$$
\begin{aligned}
& \uparrow \text { CRH - ( } \\
& \begin{array}{l}
\uparrow T_{R H}-(\text { tTSH } \\
\uparrow \mathrm{GH}_{\text {(doy) }}
\end{array}
\end{aligned}
$$

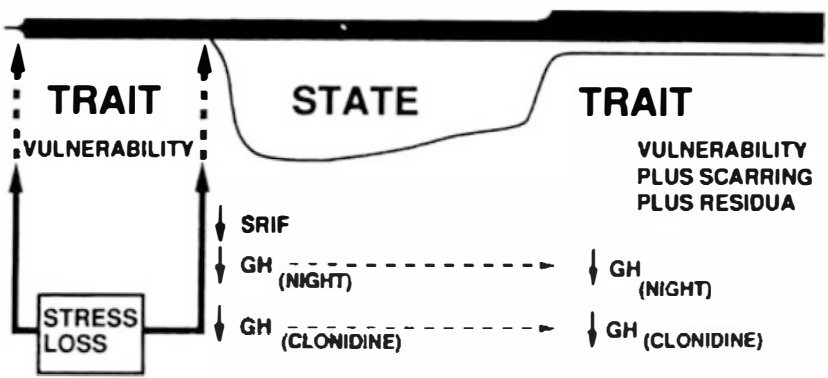

Figure 6. Progression of state-trait phenomenon over the course of affective illness SRIF = somatotropin releasinginhibiting factor (somatostatin). Adapted from Post 1992. 
is noted during the night, as well as reduced growth hormone to a clonodine challenge.

An alternative model for biologic changes has recently been posed by us (Kupfer and Ehlers 1989). Our own strategy has been to develop a model of the disorder that utilizes data on biologic correlates of recurrent depression. We have sought to emphasize a distinction between what will be referred to as Type 1 biologic correlates, or persistent features of the disorder, and Type 2 correlates, those associated with acute symptomatology (Table 3) (Kupfer and Ehlers 1989). It is suggested that Type 1 correlates might represent the very features that underlie the pathophysiology of the disorder. We believe that such correlates may represent measures of vulnerability to the disorder reflecting the major impact of genetic or familial influences. Such features are observable even in individuals who have never had an episode but who are at risk. On the other hand, they may represent biologic scars, the residual effect of having had one or more episodes of depression, as well as effects of the aging process.

In contrast, Type 2 correlates are related to the more episodic features of the disorder. Such biologic correlates may aid us in characterizing subtypes of depression, as well as in understanding specific differences between inpatients and outpatients. The characterization of the stressors that lead to hospitalization and the decreased availability or viability of social support systems in the environment could be important factors. Furthermore, an understanding of gender differences in the experience and/or nature of such stressors and support systems may lead to a more sophisticated understanding of the acute episode and episodic biologic features.

Although these biologic changes are rather evident during the state of depression, a certain number of changes seem to be persistent beyond the episode itself (Type 1). These may include physiologic changes in sleep, as well as selected endocrine changes. For ex- ample, at this point in time, an increasing consensus has led to the suggestion that reduced growth hormone is a prime example.

\section{TREATMENT OUTCOME AS A WINDOW ON PATHOGENESIS}

Because we believe that an improved understanding of the pathway to the initial episode of depression may be an important key to our overall concept of pathways to depression, we are emphasizing those factors that contribute to this initial episode. Furthermore, we also subscribe to the notion that the course of the first episode-onset and recovery and the impact of therapeutic intervention - represent essential areas to investigate specifically.

At the present time, our research efforts can be enhanced by understanding more about the role of and extent to which therapeutic intervention can play a role in treating the first episode. The first episode in many ways is very different from subsequent episodes; a level of profound dysregulation is usually present. We can ask the question of whether the therapeutic intervention can completely reverse the dysregulation, in a sense, pushing the systems back into a normal range. Does normal recovery represent a return to homeostasis and equilibrium and is there a "scar?" It is rather interesting to think about how the role of life events is perceived with respect to first episodes versus subsequent episodes.

The basic problem with the two biologic models is exactly that: they are only biologic models and they do not incorporate any psychosocial factors, and nor they are not placed in a developmental context. The question of how the next iterations of these models can be achieved is not an easy one, but numerous studies are now yielding clues to developing such an enriched model. Such findings can be derived from onset studies

Table 3. A Biologic Model of Recurrent Depression

\begin{tabular}{|c|c|c|}
\hline Biologic Correlates & $\begin{array}{c}\text { Type 1 } \\
\text { (Persistent) }\end{array}$ & $\begin{array}{c}\text { Type } 2 \\
\text { (Episodic) }\end{array}$ \\
\hline $\begin{array}{l}\text { Genetic/familial transmission } \\
\text { Slow-wave sleep alterations } \\
\text { REM sleep dysregulation } \\
\text { Gender } \\
\text { Aging } \\
\text { Stress and severity related } \\
\text { Neuropeptide factors }\end{array}$ & $\begin{array}{c}+++ \\
+++ \\
+ \\
++ \\
+++ \\
+ \\
\text { GRF }\end{array}$ & $\begin{array}{c}+ \\
+ \\
+++ \\
+ \\
+ \\
+++ \\
\text { CRF } \\
\text { (HPA axis) }\end{array}$ \\
\hline
\end{tabular}

$+=$ Minor relationship.

$++=$ Moderate level of possible relationship.

$+++=$ Strong relationship. 
or studies that focus on treatment outcome and, specifically, the recovery process. A second approach is to consider the basic units of treatments for depression with established efficacy or, at the very least, promising pilot data. For example, psychotherapeutic strategies may provide empirical data to assess the presumed role of biologic or psychosocial factors in effecting treatment outcome.

A number of factors have been suggested as facilitators of recovery including the lack of a comorbid condition such as a personality disorder, the presence of adequate social support systems, an increased level of self-esteem, the absence of or a reduction in chronic difficulties, and also the presence of "fresh starts": that is, events offering hope or relief from prior strains. These features have been derived from a variety of studies in adult-onset depression, usually in patients between 18 and 64 years of age (Kupfer and Frank 1992).

Recently, a study conducted by Karp, Frank, and colleagues (unpublished data) suggested that recovery in late-life depression may also be related to psychosocial factors. In a series of over 100 elderly individuals suffering from at least their second lifetime episode of depression who were treated with a combined drug (nortriptyline) and psychotherapy (interpersonal psychotherapy) regimen, proportional hazards modeling (univariate and multivariate) showed that only four of the 27 clinical, demographic, and psychosocial variables examined were significant in predicting slower rate of response to treatment: (1) the presence of a stressprovoking agent, such as a severely threatening life event or an ongoing major difficulty, during the 6 months before onset of illness; (2) eccentric cluster personality features; (3) a low level of tangible social support; and (4) earlier age at first episode. Median time to response was increased by 2.5 weeks (from 6.5 to 9 weeks) in the presence of a stress-provoking agent. These findings suggest a somewhat longer expected time to response among late-life patients with negative psychosocial circumstances.

It may also be useful to examine the specific treatments for depression themselves as well as selected components of those treatments to help us provide data for further modeling. Because pharmacologic data is traditionally used exclusively for these "exercises," in an effort to achieve some level of balance, we will focus on aspects of nonpharmacologic treatments. Although the role of psychopharmacologic intervention in acute treatment may be more obvious, other treatments (standardized psychotherapy treatments) are utilized successfully to manage the acute episode of unipolar depression. The first of these treatments, IPT, which was developed by Klerman and Weissman over a decade ago (Klerman et al. 1984), includes two components in dealing with a depressive episode. The first has to do with managing the depression, which in- cludes the following major issues: reviewing the symptoms of the disorder, giving these symptoms a name, explaining the prognosis, giving the patient permission to assume the sick role, and planning activities around the illness. The second part of the intervention consists of intervening in the patient's current interpersonal functioning. Difficulties are usually observed in one of four areas. The areas include unresolved grief, interpersonal role disputes, interpersonal role transitions, and interpersonal deficits.

In contrast, the rationale and approach of cognitive therapy (Beck et al. 1979) is somewhat different. It is based on the premise that depression is related to the absence of mastery or pleasure experiences in the patient's life and to dysfunctional cognitions. The assumption is that increasing mastery and pleasure experiences and the modification of these cognitions will ameliorate a mood disorder. Both of these forms of psychotherapy are very syntonic with the problems that depressed patients report and, not surprisingly, address issues demonstrated to delay recovery of the acute episode.

We now examine what factors contribute to or correlate with relapse (a failure to sustain the treatment response in the acute episode during a continuation period) and what factors contribute to recurrence (the development of a new episode); our review of the literature shows that they are not that different from those factors that may be related to the delay of recovery of the acute episode itself. The factors include two key variables that also represent features of incomplete recovery: some degree of neuroendocrine and neurophysiologic dysregulation and the ongoing presence of residual symptoms. In addition, it would appear that many of the same variables that are associated with increased risk for onset of an index episode are also associated with relapse and recurrence, such as severe life events, a history of many previous episodes, and the presence of a pathologic personality profile. Finally, controversial data sets exist on issues relating to poor social adaptation and the presence of lower tricyclic antidepressant plasma levels on an equivalent dose.

To demonstrate how incomplete recovery or the persistence of subsyndromal symptoms relate to relapse and recurrence, Keller and colleagues (1992) showed that in bipolar patients, the presence of hypomanic subsyndromal features lead directly to the later occurrence of mania in the majority of cases (Table 4). In situations in which the subsyndromal features were of a depressive nature, the relapse into depression and/or mania was still increased compared to what would be likely based on naturalistic data sets.

One way of conceptualizing recurrent mood disorders (or certainly bipolar disorder) has been suggested by Goodwin and Jamison (1990) who promoted an instability model of the pathophysiology of bipolar 
Table 4. Relationship of First Subsyndromal Symptom Type to Subsequent Major Relapse Type

\begin{tabular}{lcccc}
\hline & \multicolumn{4}{c}{ Relapse Type } \\
\cline { 2 - 5 } Subsyndromal & None & Depression & Mania & Mixed \\
Symptom Type & 20 & 4 & 0 & 0 \\
Depressive & 4 & 2 & 11 & 0 \\
Hypomanic & 0 & 0 & 0 & 1 \\
Mixed & & & &
\end{tabular}

Adapted from Keller et al. 1992.

disorder. Although their model included genetic vulnerability, stress, neurotransmitter dysregulation, circadian rhythm dysregulation, and the obvious presence of symptoms and behavioral disturbances, we believe that components related to rhythm dysregulation, behavior, and especially interpersonal stress can in fact be thought of as issues that must be addressed to achieve complete recovery. Indeed, our own notions on this matter, which point to the importance of social zeitgebers or social timekeepers to help stabilize rhythms, have been incorporated into a model of how the SCN or the biologic clock may function (Ehlers et al. 1988). We argue that it depends on input not only from physical zeitgebers but social zeitgebers and that, in turn, then affects circadian effector systems (Fig. 7). This translates into an approach to treatment of individual patients that includes an emphasis on stabilizing social rhythms (Frank et al. unpublished data).

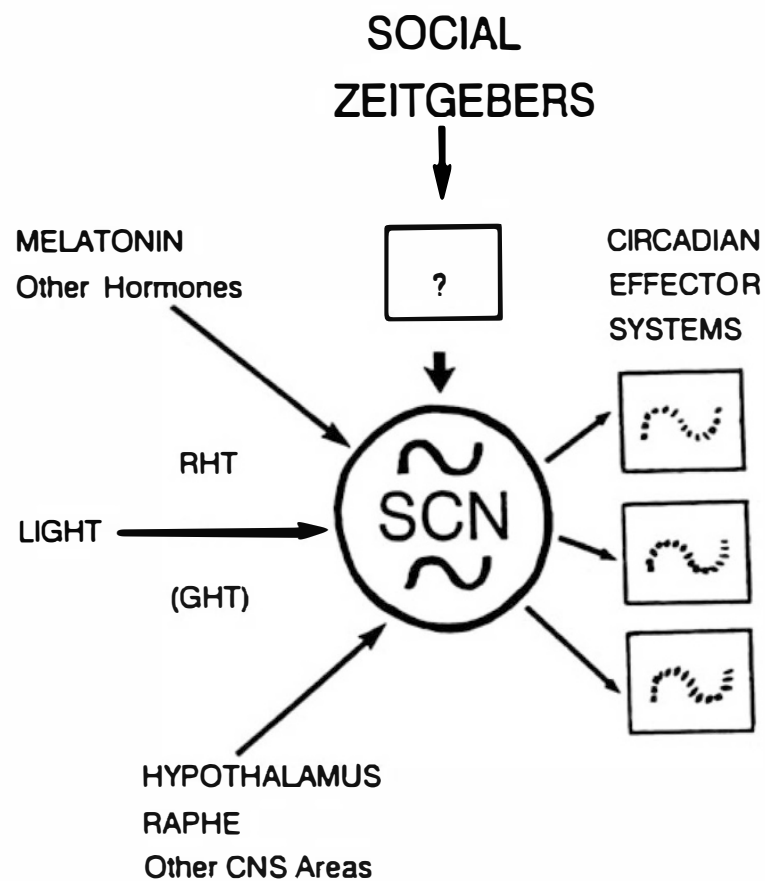

Figure 7. Hypothetical human circadian timing system. Adapted from Moore 1991.
In a treatment approach currently being investigated at the University of Pittsburgh, Frank and colleagues (unpublished data) are utilizing both social rhythm stabilization and features of interpersonal psychotherapy to develop a psychosocial intervention for bipolar disorder as an adjunct to pharmacologic treatment, with the major aims of achieving complete recovery from an episode and then sustaining the recovery. In an effort to stabilize social rhythms, the therapist's first task is to find the patient's most unstable daily rhythms (e.g., a highly irregular sleep-wake schedule), then set goals for change in those rhythms, moving gradually and making certain that expectations for change are reasonable. The therapist also helps the patient identify triggers to rhythm disruption. Once those areas have been fully explored, the therapist investigates with the patient how to achieve the right balance in terms of how much rest, how much activity, and how much stimulation is ideal for that particular individual. The therapist and patient then develop strategies to maintain the balance and, with'n that maintenance plan, how to adapt to changes in routine, some of which may be planned and others unexpected.

In addition to rhythm stability and biological dysregulation, we believe that the appearance of subsyndromal symptomatology following a complete recovery and incomplete recovery are important considerations. Once an individual has had one or two episodes of either unipolar or bipolar disorder, it appears that there is a certain level of autonomy of the disorder. In fact, Post and others have suggested that continuing dysregulation, both biologic and nonbiologic, may reflect a more and more autonomous expression of the disorder. Another view, however, is that recurrences occur because of incomplete recovery. This may, in fact, represent a failure to regain homeostatis or a return only to the preepisode subclinical state. (Keller and others described a similar clinical state as "double depression." Keller and Shapiro, 1982.)

Thinking about treatment success or failure from a developmental perspective may also provide a window on pathogenesis. For example, at what age do antidepressants begin to work? The current status of treat- 
ment research on antidepressants in prepubital and adolescent depression suggests that there is no definitive efficacy for antidepressant drugs. At this point, not enough treatment trials using the recent modifications of IPT (Klerman and Weissman 1992) or cognitive therapy (Wilkes et al. in press) in adolescent depression have been conducted to assess the efficacy for nonpharmacologic intervention. Does the age at which antidepressants begin to work coincide with the age when biologic stigmata, on a consistent basis, is noted in clinical depression? Hence, an important question may be to determine the age of onset for various biologic stigmata in depression because this, in turn, may give us clues with respect to treatment approaches in depression.

Another important issue that has been underplayed up to the present time is the role of gender differences in determining treatment strategies. Thus far, data does suggest that psychopharmacologic treatment appears to be fairly gender blind (Frank submitted), as does cognitive therapy (Thase et al. unpublished data). However, with respect to both short-term and long-term IPT, there may indeed be gender differences in treatment efficacy.

Other questions that involve neurobiology and treatment approaches have to do with whether we can use biologic indictors to determine which patients will benefit from maintenance treatment, both in terms of somatic treatment and nonsomatic treatments. These questions can be answered within the next decade as long as both biologic researchers work in an integrated fashion.

\section{CONCLUSIONS}

From this brief review on pathways to depression and selected treatment issues, we conclude that we are still faced with several major unresolved problems. These include the following: the role of life experience in depression, delineation of psychopathologic states from normal emotional reactions, improved classification and differentiation of types of depression, the need for better predictors of treatment response, and social and clinical criteria for outcome studies. These are not new problems; indeed, these were the very questions posed by Gerald Klerman in a landmark paper published in the Archives of General Psychiatry some 21 years ago (Klerman 1971). He concluded his review of clinical research in depression "Circa 1971" by suggesting that we best operate in the borderline between clinical research, biologic investigations, and theoretical speculation. It is still easy to agree with his final comment, which was that new models and new facts are needed to better integrate clinical research data, to generate new strategies, and ultimately new ideas. The ultimate mission of therapeutics is to help our patients, but at the same time it is to help us better understand the disorders that we are treating.

\section{ACKNOWLEDGMENTS}

This work was supported in part by a grant from the John D. and Catherine T. MacArthur Foundation Research Network on the Psychobiology of Depression. I would like to acknowledge the assistance of Ellen Frank, Ph.D.

\section{REFERENCES}

Beck AT, Rush AJ, Shaw BF, Emery G (1979): Cognitive Therapy of Depression. New York, Guilford Press

Bifulco A, Brown W, Adler Z (1991): Early sexual abuse and clinical depression in adult life. Br J Psychiatry 159: $115-122$

Brown GW, Harris TO (1978): Social Origins of Depression: A Study of Psychiatric Disorders in Women. London, Tavistock

Brown GW, Harris TP, Bifulco A (1986): Long-term effects of early loss of parent. In Rutter M, Izard C, Read P (eds). Depression in Childhood: Developmental Perspectives. New York, Guilford Press

Dahl RE, Puig-Antich J, Ryan ND, Nelson B, Dachille S, Cunningham SL, Trubnick L, Klepper TP (1990): EEG sleep in adolescents with major depression: The role of suicidality and inpatient status. J Affect Disord 19:63-75

Dahl RE, Ryan ND, Puig-Antich J, Nguyen NA, Al-Shabbout M, Meyer VA, Perel J (1991): 24-hour cortisol measures in adolescents with major depression: A controlled study. Biol Psychiatry 30:25-36

Dawson G, Grofer Klinger L, Panagiotides H, Hill D, Spieker $S$ (1992a): Frontal lobe activity and affective behavior of infants of mothers with depressive symptoms. Child Dev 63:723-737

Dawson G, Grofer Klinger L, Panagiotides H, Spieker S (1992b): Infants of mothers with depressive symptoms: Electroencephalographic and behavioral findings related to attachment status. Dev Psychopathol 4:67-80

Ehlers CL, Frank E, Kupfer DJ (1988): Social zeitgebers and biological rhythms: A unified approach to understanding the etiology of depression. Arch Gen Psychiatry 45:958-952

Frank E (submitted): Gender and depression: Similarities and differences between men and women. JAMA

Goodwin FK, Jamison KR (1990): Manic-depressive illness. London, Oxford University Press

Hammen C (1992): The family-environmental context of depression: A perspective on children's risk. In Cicchetti D, Toth SL (eds), Developmental Perspectives on Depression. New York, University of Rochester Press, pp 251-281

Kagan J, Reznick JS, Snidman N (1988): Biological bases of childhood shyness. Science 240:167-171

Kagan J, Snidman N (1991a): Temperamental factors in human development. Am Psychol August: 856-862 
Kagan J, Snidman N (1991b): Infant predictors of inhibited and uninhibited profiles. Psychol Sci 2:40-44

Keller MB, Lavori PW, Kane JM, Gelenberg AJ, Rosenbaum JR, Walzer EA, Baker LA (1992): Subsyndromal symptoms in bipolar disorder: A comparison of standard and low serum levels of lithium. Arch Gen Psychiatry 49: 371-376

Keller MB, Shapiro RW (1982): “Double depression": Superimposition of acute depressive episodes on chronic depressive disorders. Am J Psychiatry 139:438-442

Klerman GL (1971): Clinical research in depression. Arch Gen Psychiatry 24:305-319

Klerman GL (1975): The broadening scope of research in depressive disorders (Editorial). J Nerv Ment Dis 160:3-4

Klerman GL (1983): The efficacy of psychotherapy as the basis for public policy. Am Psychol August: 929-934

Klerman GL (1990): Paradigm shifts in USA psychiatric epidemiology since World War II. Soc Psychiatry Psychiatr Epidemiol 25:27-32

Klerman GL, Weissman MM (1992): Interpersonal psychotherapy. In Paykel ES (ed), Handbook of Affective Disorders, 2nd Ed. Edinburgh, Churchill Livingstone, pp 501-510

Klerman GL, Weissman MM, Rounsaville BJ, Chevron ES (1984): Interpersonal Psychotherapy of Depression. New York, Basic Books

Koob GF, Ehlers CL, Kupfer DJ (1989): Animal Models of Depression. Boston, Birkhauser

Kraemer GW (1992): A psychobiological theory of attachment. Behav Brain Sci 15:493-541

Kupfer DJ, Ehlers CL (1989): Two roads to rapid eye movement latency. Arch Gen Psychiatry 46:945-948

Kupfer DJ, Frank E (1992): The minimum length of treatment for recovery. In Montgomery SA, Rouillon F (eds), Long- term Treatment of Depression. England, John Wiley and Sons, pp 33-52

Lauer CJ, Riemann D, Wiegand M, Berger M (1991): From early to late adulthood changes in EEG sleep of depressed patients and healthy volunteers. Biol Psychiatry 29: 979-993

Moore RY (1991): Disorders of circadian function and thehuman circadian timing system. In Klein DC, Moore RY, Reppert SM (eds). Suprachiasmatic Nucleus: The Mind's Clock. New York, Oxford University Press, pp 429-441

Post RM (1992): Transduction of psychosocial stress into the neurobiology of recurrent affective disorders. Am J Psy. chiatry 149:999-1010

Puig-Antich J (1986): Psychobiological markers: Effect of age and puberty. In Rutter M, Izard CE, Read PB (eds), Depression in Young People: Developmental and Clinical Perspectives. New York, Guilford Press, pp 341-348

Puig-Antich J, Dahl R, Ryan N, NovacenkoH, Goetz D, Goetz R, Twomey J, Klepper T (1989): Cortisol secretion in prepubertal children with major depressive disorder. Arch Gen Psychiatry 46:801-809

Puig-Antich J, Goetz R, Hanlon C, Davies M, Thompson J, Chambers WJ, Tabrizi MA, Weitzman ED (1982): Sleep architecture and REM sleep measures in prepubertal children with major depression: A controlled study. Arch Gen Psychiatry 39:932-939

Rogeness GA, Javors MA, Pliszka SR (1992): Neurochemistry and child and adolescent psychiatry. J Am Child Adolesc Psychiatry 31:765-781

Sachar EJ (1982): Endocrine abnormalities in depression. In Paykel ES (ed), Handbook of Affective Disorders. New York, Guilford Press, pp 191-201

Wilkes TCR, Belsher G, Rush AJ, Frank E (1993): Cognitive Behavior Therapy for Depressed Adolescents (CBT-A). New York, Guilford Press (In press) 